\title{
Behavioural, attitudinal and dietary responses to the consumption of wholegrain foods
}

\author{
A. T. Smith ${ }^{1}$, S. Kuznesof ${ }^{1}$, D. P. Richardson ${ }^{2}$ and C. J. Seal ${ }^{1 *}$ \\ ${ }^{1}$ Human Nutrition Research Centre, School of Agriculture, \\ Food and Rural Development, University of Newcastle, Newcastle upon Tyne NE1 7RU, UK \\ ${ }^{2}$ Nestlé UK Ltd, St George's House, Croydon CR9 1NR, UK
}

\begin{abstract}
Whole grains are important dietary constituents as they provide a plethora of nutrients and protective chemicals that may have synergistic actions in promoting health. Regular consumption of wholegrain foods has been associated with a reduced risk of several chronic diseases such as CHD and certain cancers, although their exact role in disease prevention is not yet fully elucidated. Studies reporting levels of whole grain consumption reveal that those subjects who include higher levels of whole grain foods in their diets also have many other favourable dietary and lifestyle practices. While the actions of these practices and whole grains may not be mutually exclusive, these variables do not appear to explain the reduction in risk of disease observed for high-whole grain consumers. Actual whole grain consumption levels are extremely low and many practical barriers exist to consumer uptake of these foods. Effective communication of the whole grain health message is an important strategy to increase awareness of the importance of whole grains in the diet. Increasing the variety and availability of acceptable wholegrain foods is also important. Whole grain consumption at breakfast can have an important impact on total daily nutrient intakes. This simple dietary modification is potentially relatively easy to achieve and could greatly contribute to increased whole grain intake for many individuals.
\end{abstract}

Whole grain: Consumption: Behaviour: Diet

The cereal grains consumed by man and animals are derived from seeds of domesticated members of the grass family Gramineae (Southgate, 2000). They are important plant foods in the human diet as they constitute dietary staples in most countries and provide two-thirds of the energy and protein intake worldwide (Slavin et al. 2000). In the UK cereal foods provide (\% intake): energy approximately 30 ; protein 25; available carbohydrate approximately 50; while $>70 \%$ of the energy intake in many parts of rural Africa and Asia is from cereal sources (Southgate, 2000). The major cereal grains include wheat, rice and maize. Wheat accounts for one-third and rice one-quarter of the total grain production worldwide. Barley, sorghum, millets, rye and oats are the minor cereal grains (Slavin et al. 2000). The type of grain consumed as a staple food varies geographically according to climatic compatibility (Southgate, 2000). Wheat is the most common cereal in the diets of individuals from temperate countries, with rice being more important in the Far Eastern countries and maize in much of Africa and Central America. Barley is primarily produced for animal feed and for use in the brewing and distilling industries. Sorghum is a staple crop in many parts of Africa due to its resistance to drought conditions. Millets include the grains of several species popular in African countries. Rye is an important crop of cooler climates and is found in Scandinavia and Central Europe as an alternative to wheat (Southgate, 2000). In the USA oats are important grains as they are generally eaten whole and therefore constitute an important part of whole-grain consumption (Slavin et al. 2000).

\section{Grains and nutrition}

Although grains form the dietary staples for most cultures, the vast majority of grains produced in Westernised countries are eaten as refined-grain products (Richardson, 2000).

Whole grains comprise three main layers: the bran; the endosperm; the germ (see Fig. 1). Although categorised as 'carbohydrates', grains deliver much more than carbohydrate to our nutrient intakes. Whole grains are important 


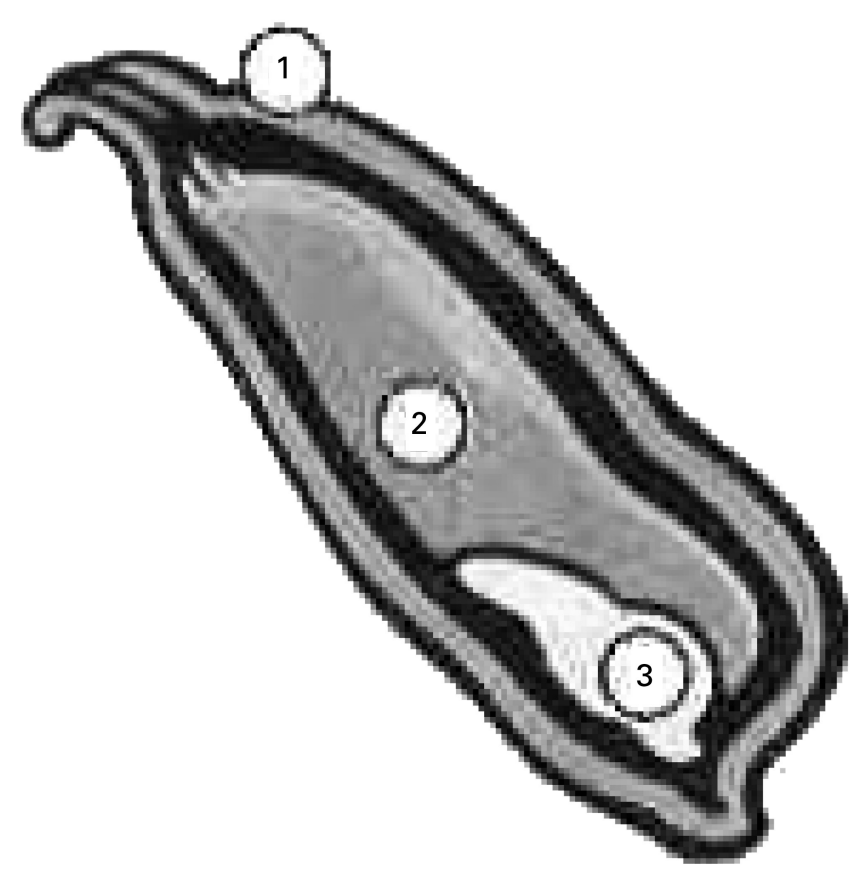

Fig. 1. Cross-section through a wheat grain showing major structural compartments. 1, bran, which provides fibre, B-vitamins, minerals, protein and phytochemicals; 2, endosperm, which contains carbohydrates, proteins and small amounts of B-vitamins; 3 , germ, which contains high concentrations of minerals, B-vitamins, vitamin $E$ and other phytochemicals. (Adapted from British Nutrition Foundation, 2001.)

sources of dietary fibre and resistant starch. Wheat is a valuable source of insoluble dietary fibre, while oats and barley contribute soluble fibre to our diets, mainly in the form of $\beta$-glucans. Grains are also major sources of plant proteins. Vegetable sources of protein are often regarded as inferior in quality compared with animal sources, but they can be easily combined within meals to form complete proteins. Grains also serve as important sources of many vitamins including vitamin $\mathrm{B}$ complex and vitamin $\mathrm{E}$, and many minerals including $\mathrm{Fe}, \mathrm{Mg}$, Se and $\mathrm{Zn}$. Most of these nutrients are concentrated in the outer bran and germ layers, although the endosperm contains much of the starch and protein as well as considerable quantities of riboflavin and pantothenic acid (Southgate, 2000). Many of these nutrients are of particular importance due to their functions in disease prevention. Dietary fibre is acknowledged by many authorities to play a crucial role in intestinal health (Cummings et al. 1992; Stephen, 1994). Folate intake is pertinent, especially for pregnant women, in the prevention of neural-tube defects (Cuskelly et al. 1996), as well as in its role, in conjunction with other B-vitamins, in lowering plasma homocysteine concentrations, a known risk factor for coronary disease (Ward, 2001). Vitamin E, including the tocotrienols, and various trace minerals found in whole grains, such as $\mathrm{Cu}, \mathrm{Zn}$, Se and $\mathrm{Mn}$, are natural antioxidants.

\section{Protective components}

In addition to these nutrients, whole grains contain many different protective chemicals or 'phytochemicals' believed to confer health benefits (Craig, 1997). Such substances include various antioxidants, phyto-oestrogens and oligosaccharides. The antioxidants found in whole grains are mostly the same or similar to those contained in fruit and vegetables, but many are also unique (Miller et al. 2000a). They include natural antioxidants such as vitamin $\mathrm{E}$ and trace minerals, and other components such as phenolic acids, lignans and phytic acid. The antioxidant content of whole grains is less than that of some berries, but greater than that of common fruits or vegetables (Miller et al. 2000b). Antioxidants are important anticarcinogenic agents due to their role in balancing oxidative reactions and counteracting oxidative stress within the body (Thompson, 1994; Andlauer \& Furst, 1998; Baublis et al. 2000a). $\mathrm{O}_{2}$ is a substrate for many crucial metabolic processes; however, oxidation can also promote the formation of free radicals and other toxic oxygen species that damage cellular material and can lead to the development of several chronic diseases, including atherosclerosis and cancer (Baublis et al. 2000a). Whole grains contain many compounds capable of preventing or minimising oxidative damage, including the antioxidant phytic acid and numerous phenolic compounds. These components are present in substantial concentrations in normal servings of wheat-based breakfast cereals, and the digestion process may further enhance their actions (Baublis et al. 2000b). Epidemiological evidence shows an inverse relationship between CHD risk and antioxidant intake (Rimm et al. 1993; Knekt et al. 1994).

Phyto-oestrogens are compounds with structures similar to that of oestrogen, and those found in whole grains include isoflavones, coumestans and lignans. They are of interest due to their capacity to alter the pattern of serum hormones during the menstrual cycle and improve post-menopausal symptoms such as 'flushes' and vaginitis (Shoff et al. 1998; Slavin et al. 2000). Phyto-oestrogens have been implicated as natural cancer-protective compounds through their influence on sex hormone metabolism and biological activity, and intracellular enzymes, protein synthesis, growth factor action, malignant cell proliferation, differentiation and angiogenesis (Adlercreutz, 1995, 2002; Adlercreutz \& Mazur, 1997; Kurzer \& Xu, 1997).

Naturally-occurring oligosaccharides found in cereal grains include fructans, inulin and oligofructose. In the human gut they display characteristics similar to those of soluble NSP and may therefore be useful in improving blood lipid profiles and glucose control (Slavin, 1999). Oligosaccharides have the ability to alter the balance of human faecal microflora promoting a 'healthier' gut environment, which may be linked to improved immune function (Slavin et al. 2000). Oligosaccharides have further functional properties, including the ability to serve as sweetening and fat-replacement agents (Slavin, 1999).

These various protective chemicals, which occur naturally in whole grains, have important implications for health and disease prevention.

\section{Effects of processing}

In preparation for human consumption grains are usually subjected to some type of processing. This grain treatment is useful in terms of enhancing various organoleptic properties 
to optimise consumer acceptance, producing shelf-stable products and conditioning the product for digestion and absorption. During processing, the milling procedures remove contaminants but also remove the nutrient-rich bran and germ layers from the starchy endosperm. The finelyground endosperm is used to make white flour. Refined white flours are termed 'low extraction' as they constitute only a small proportion of the original grain (Southgate, 2000). A 'high-extraction' flour, approximately $100 \%$ extraction rate, produces a wholemeal flour (Slavin et al. 2000). The milling process concentrates the carbohydrate and reduces the concentrations of other macronutrients, vitamins and minerals due to the removal of the outer layers (Slavin et al. 2000). In addition, although cereals are low-Na foods, some processed cereal products are among the foods with the highest $\mathrm{Na}$ levels consumed because $\mathrm{Na}$ is added during the manufacturing process (Truswell, 2002). Table 1 compares the nutritional content of wholemeal and white flours. All nutrients with potential preventive actions against disease are reduced. Some nutrients, e.g. Se, Mn, vitamin E and $\mathrm{Zn}$, are reduced by as much as 79-92 \%. It is suggested, however, that the overall antioxidant capacity is altered mostly qualitatively, in that natural antioxidants lost during processing may be compensated for by the formation of compounds with new antioxidant properties during thermal treatment of the grain (Slavin et al. 2000).

Although optimisation of grains for consumer acceptance is an important function of processing, refinement of grains results in considerable nutritional losses. Certain nutrients, including $\mathrm{B}$-vitamins, $\mathrm{Fe}, \mathrm{Ca}$ and folic acid, may be

Table 1. Nutrient content $(/ \mathrm{kg})$ in wholemeal and white flours (adapted from Truswell, 2002)

\begin{tabular}{|c|c|c|c|}
\hline & $\begin{array}{l}\text { Wholemeal } \\
\text { flour }\end{array}$ & White flour* & (\%) Change \\
\hline Protein $(\mathrm{g})$ & 127 & 94 & -26 \\
\hline Fat $(g)$ & 22 & 13 & -41 \\
\hline Carbohydrate (g) & 639 & 777 & +22 \\
\hline Starch $(g)$ & 618 & 762 & +23 \\
\hline Sugars (g) & 21 & 15 & -29 \\
\hline Fibre† (g) & 90 & 31 & -66 \\
\hline $\mathrm{Na}(\mathrm{mg})$ & 30 & 30 & 0 \\
\hline $\mathrm{K}(\mathrm{mg})$ & 3400 & 1500 & -56 \\
\hline $\mathrm{Ca}(\mathrm{mg})$ & 380 & 150 & -61 \\
\hline $\mathrm{Mg}(\mathrm{mg})$ & 1200 & 200 & -83 \\
\hline$P(\mathrm{mg})$ & 3200 & 1100 & -66 \\
\hline $\mathrm{Fe}(\mathrm{mg})$ & 39 & 15 & -62 \\
\hline $\mathrm{Cu}(\mathrm{mg})$ & 4.5 & 1.5 & -67 \\
\hline $\mathrm{Zn}(\mathrm{mg})$ & 29 & 6 & -79 \\
\hline $\mathrm{Cl}(\mathrm{mg})$ & 380 & 810 & +113 \\
\hline $\mathrm{Mn}(\mathrm{mg})$ & 31 & 6 & -81 \\
\hline Se $(\mu \mathrm{g}$ & 530 & 40 & $\begin{array}{l}-01 \\
-92\end{array}$ \\
\hline Vitamin E (mg) & 14 & 3 & -79 \\
\hline Thiamin (mg) & $4 \cdot 7$ & 1 & -79 \\
\hline Riboflavin (mg) & $\begin{array}{l}4 \cdot 7 \\
0.9\end{array}$ & 0.3 & $\begin{array}{l}-19 \\
-67\end{array}$ \\
\hline Niacin (mg) & 57 & 7 & \\
\hline Vitamin $B_{6}(\mathrm{mg})$ & $\begin{array}{r}5 / \\
5\end{array}$ & 1.5 & $\begin{array}{l}-88 \\
-70\end{array}$ \\
\hline Folate $(\mu \mathrm{g})$ & $\begin{array}{r}5 \\
570\end{array}$ & 220 & $\begin{array}{l}-70 \\
-61\end{array}$ \\
\hline Pantothenate $(\mathrm{mg})$ & 570 & 3 & -61 \\
\hline Biotin $(\mu \mathrm{g})$ & 8 & 3 & -63 \\
\hline & 70 & 10 & -86 \\
\hline
\end{tabular}

*Unfortified.

†NSP (Englyst \& Cummings, 1998). reintroduced into the refined grain through the processes of restoration and fortification. While consumption of fortified grains has considerable implications for intakes of specific nutrients, it overlooks the synergistic effects that these and other nutrients and non-nutrients naturally abundant in whole grains may exert to confer their health benefits.

\section{Health benefits of whole grains}

There is now increasing evidence from a variety of sources supporting the precept that consumption of whole grains may reduce the risk of a wide range of non-communicable diseases, including CHD, some cancers and type 2 diabetes. This evidence is largely underpinned by epidemiological data showing associations between intake and relative risk of disease or odd ratios for incidence. Table 2 shows a summary of some of the reported associations, which will be discussed in more detail in the following sections.

\section{Whole grains and heart disease}

In an early study (Morris et al. 1977) forty-five of 337 healthy middle-aged men, who were followed for 10-20 years, developed clinical CHD. The results showed that men with higher energy intakes had a lower rate of disease than the rest of the group, which was justified by their higher physical activity levels. More difficult to reason at the time and independent of energy intake was the observation that men with higher intakes of dietary fibre from cereals were also less likely to develop CHD. Other researchers subsequently reported similar associations, with several large epidemiological studies now documenting an inverse association between CHD and intake of whole grains or fibre from cereals.

No single dietary constituent or lifestyle factor is necessarily causative in the aetiology of CHD, as demonstrated by $\mathrm{Hu}$ et al. (2000) in the Health Professionals Follow-up Study. This study began in 1986 with 51529 US males, aged 40-75 years, of various professions including dentistry, optometry, pharmacy, podiatry and veterinary medicine. Of those recruited, 44875 were free from any cardiovascular diseases (CVD) at baseline, had a reported daily energy intake of between $3 \cdot 3$ and $17 \cdot 6 \mathrm{MJ}$, completed detailed dietary questionnaires and were followed for 8 years. During follow-up (311606 person-years) 1089 incident cases of CHD were documented (730 non-fatal myocardial infarctions and 359 fatal cases of CHD). Two main dietary patterns, termed 'prudent pattern' and 'Western pattern', unfolded during factorial analysis of the data. The "prudent pattern' contained heavy factor loading of vegetables, legumes, whole grains, fruit, fish and poultry, while the 'Western pattern' contained heavy factor loading of red meat, processed meat, refined grains, sweets and desserts, French fries and high-fat dairy products. The age-adjusted relative risks (RR) across increasing quintiles of 'prudent pattern' score were $1 \cdot 0,0 \cdot 84,0 \cdot 76,0 \cdot 71$ and $0.66(95 \% \mathrm{CI}$ $0.54,0.80 ; P<0.0001$ for trend). With further adjustment for smoking and other CHD risk factors the association remained highly significant, with an RR of $0.70(95 \% \mathrm{CI}$ $0.56,0.86 ; P=0.0009)$ in the highest quintile of the "prudent pattern' compared with the lowest quintile. In contrast, the 
Table 2. Summary of evidence relating reduced risk of $\mathrm{CHD}$ and cancers to increased consumption of wholegrain foods, including studies where cereal fibre intake is taken as a surrogate marker of whole grain intake

\begin{tabular}{|c|c|c|c|}
\hline Evidence for reduced risk of: & Study & Reported Association & Reference \\
\hline $\mathrm{CHD}$ & Health Professionals Follow-up Study & $\begin{array}{l}\text { yLower RR with consumption of 'prudent diet' } \\
\text { containing whole grains }\end{array}$ & Hu et al. (2000) \\
\hline Myocardial infarction & Health Professionals Follow-up Study & yLower RR with increased cereal-fibre consumption & Rimm et al. (1996) \\
\hline $\mathrm{CHD}$ & Nurses' Health Study & Lower RR with increased cereal-fibre consumption & Wolk et al. (1999) \\
\hline Coronary death & $\begin{array}{l}\alpha \text {-Tocopherol, } B \text {-Carotene Cancer } \\
\text { Prevention Study }\end{array}$ & Lower RR with increased cereal-fibre consumption & Pietinen et al. (1996) \\
\hline IHD & lowa Women's Health Study & Lower RR for increasing whole grain consumption & Jacobs et al. (1998b) \\
\hline Ischaemic stroke & Nurses' Health Study & Lower RR for increasing whole grain consumption & Liu et al. (2000a) \\
\hline \multicolumn{4}{|l|}{ Cancers } \\
\hline Colon cancer & $\begin{array}{l}\text { Case-controlled study with colon } \\
\text { cancer patients }\end{array}$ & $\begin{array}{l}\text { Reduced OR of cancer risk with increased whole } \\
\text { grain consumption }\end{array}$ & Levi et al. (1999) \\
\hline Upper GI tract cancers & & $\begin{array}{l}\text { Reduced OR of cancer risk with increased whole } \\
\text { grain consumption }\end{array}$ & $\begin{array}{l}\text { Bosetti et al. (2000) } \\
\text { Levi et al. (2000) }\end{array}$ \\
\hline
\end{tabular}

RR, relative risk; HRR, hazards rate ratio; OR, odds ratio; GI, gastrointestinal.

age-adjusted RR across increasing quintiles of the 'Western pattern' were $1 \cdot 0,1 \cdot 21,1 \cdot 24,1.24$ and 1.45 (95 \% CI 1.19 , 1.77; $P<0.0001$ for trend). These findings emphasise the importance of a healthy balanced diet in preventing disease and further demonstrate the importance of whole grain consumption as a component of this lifestyle.

In another analysis of the Health Professionals Follow-up Study (Rimm et al. 1996), significant inverse associations between dietary fibre and myocardial infarction were found. The multivariate RR for men in the highest quintile of dietary fibre intake (median $28.9 \mathrm{~g} / \mathrm{d}$ ) was $0.64(95 \% \mathrm{CI}$ $0.47,0.87 ; P=0.004$ for trend) compared with men in the lowest quintile of intake (median $12.4 \mathrm{~g} / \mathrm{d}$ ). In multivariate analysis for fibre from cereals, vegetables and fruit, cereal fibre showed the strongest negative association, with a RR of 0.71 (95\% CI $0.55,0.91 ; P=0.007$ for trend) for men in the highest quintile of cereal fibre intake compared with those in the lowest quintile of intake. This association remained essentially unchanged with further adjustment for carotene, folate and vitamin $\mathrm{B}_{6}$ intakes (RR 0.73 (95\% CI $0 \cdot 57,0.94)$ ).

Wolk et al. (1999) found similar associations between dietary fibre intake and risk of CHD in women participating in the Nurses' Health Study (multivariate RR 0.77 (95 \% CI $0.57,1.04 ; P=0.07$ ) for women in the highest quintile of dietary fibre intake $(22.6 \mathrm{~g} / \mathrm{d})$ compared with those in the lowest quintile of intake $(10.9 \mathrm{~g} / \mathrm{d}))$. Again, cereal fibre showed the strongest inverse association with CHD risk compared with fruit or vegetable fibre (multivariate RR 0.66 (95\% CI $0.49,0.88) ; P<0.001$ for trend) for women in the highest quintile of cereal fibre intake compared with those in the lowest quintile of intake.

The Alpha-Tocopherol, Beta-Carotene Cancer Prevention Study followed 21930 male smokers aged 50-60 years for
6 years (Pietinen et al. 1996). This study was a randomised double-blind placebo-controlled prevention trial in which subjects were given supplements of a-tocopherol and/or $\beta$-carotene. Participants were free from CVD at baseline and dietary information was gathered using a 276-item questionnaire. During follow-up there were 1399 major coronary events, of which 635 were fatal CHD cases. Dietary fibre was found to be inversely associated with coronary death. The RR for coronary death was 0.69 (95 \% CI 0.54, 0.88; $P<0.001$ for trend) for men in the highest quintile of total dietary fibre intake (median $34.8 \mathrm{~g} / \mathrm{d}$ ) compared with men in the lowest quintile of intake (median $16.1 \mathrm{~g} / \mathrm{d}$ ). Adjustment for known CVD risk factors, intake of saturated fat, $\beta$-carotene, vitamin $\mathrm{C}$ and vitamin $\mathrm{E}$ did not alter the association. Coronary deaths were more strongly negatively associated with cereal fibre intake than fibre from fruit or vegetables.

In a study of 34198 male and female Californian Seventh Day Adventists reported by Fraser (1999) nut intake was most consistently associated with reduced risk of both fatal and non-fatal IHD. Preference for wholegrain bread was, however, also a predictor. The multivariate RR among those who preferred wholegrain bread was 0.89 for fatal IHD $(P<0.005)$ and 0.56 for non-fatal IHD $(P<0.01)$ compared with subjects who preferred white bread.

In the Norwegian County Study Jacobs et al. (2001) found a similar inverse association between wholegrain bread consumption and disease. Their study used a semiquantitative food-frequency questionnaire (FFQ) to gather dietary information from 33848 Norwegian males and females aged 35-65 years. The multivariate hazard rate ratios for those in the highest quintile of wholegrain-bread score compared with those in the lowest quintile was 0.66 (95\% CI $0.57,0.77 ; P<0.0001$ for linear trend) for total 
deaths; 0.76 (95 \% CI 0.56, 1.02; $P=0.04$ for linear trend) for CHD deaths and 0.77 (95\% CI $0.60,0.98 ; P=0.016$ for linear trend) for CVD deaths. This study survey contained little information on fruit or vegetable intake; hence the findings for whole grain may in part reflect the positive influence of fruit and vegetable intake.

Few studies have addressed directly the relationship between intake of wholegrain food and disease risk reduction, with most studies using cereal fibre as a surrogate marker of whole grain consumption. Such an investigation was undertaken, however, with The Iowa Women's Health Study (Jacobs et al. 1998b, 1999, 2000). In this prospective cohort study a total of 41836 post-menopausal US women aged 55-69 years were followed for 9 years. Participants were free from heart disease at baseline and completed a 127-item FFQ for dietary assessment. Whole grain consumption varied considerably from a median intake of 1.5 servings per week in the lowest quintile to 22.5 servings per week in the highest quintile of intake (see Table 3). The results show an inverse association between whole grain consumption and total mortality risk, with a $40 \%$ reduction in age- and energy-adjusted risk for women with a daily intake of whole grains (Jacobs et al. 1999). Similar reductions in death rate were observed for major causes of death, except stroke, with increased whole grain consumption. In contrast, there was evidence of a small positive association between refined grain intake and increased risk of total mortality (RR $1.16(95 \%$ CI $1.01,1.33) ; P=0.04$ for trend) for those in the highest quintile of refined grain intake compared with those in the lowest quintile of intake (Jacobs et al. 1999). Jacobs et al. (1998b) found a strong inverse association between whole grain intake and risk of death from IHD. For total whole grain intake across increasing quintiles of intake the age- and energy-adjusted RR were $1.00,0.84,0.58,0.45$ and 0.60 (95\% CI 0.45, 0.81; $P=0.0002$ for trend). Multivariate analysis, adjusted for several dietary and lifestyle factors, showed an attenuation of the inverse relationship, but the association still remained (RR 0.70 (95\% CI 0.50, 0.98); $P=0.018$ ) for the highest quintile of whole-grain consumption compared with the lowest quintile of consumption. There was little evidence of an association between total refined grain intake and risk of IHD. A perplexing finding in the relationship between whole grain intake and risk of CHD and all-cause mortality is the upturn in observed risk in the highest quintile of whole grain intake compared with the preceding quintile of intake. This observation could be interpreted as a protection threshold level for intakes above the intake of the fourth quintile (median thirteen servings per week).

The Nurses' Health Study, a prospective cohort of 75521 US women aged 38-63 years was used to further examine the relationship between whole grain intake and risk of ischaemic stroke (Liu et al. 2000b) and heart disease (Liu et al. 1999) in women. Participants who were free from diabetes, CHD, stroke or other CVD at baseline completed a semi-quantitative FFQ at baseline and during the 10 years of follow-up. Median intakes of whole grain at baseline ranged from $0 \cdot 13$ servings per $d$ in the lowest quintile of intake to 2.70 servings per $d$ in the highest quintile of intake. Over the 10-year follow-up period whole grain intake increased from a mean of $1 \cdot 12$ servings per $d$ to $1 \cdot 36$ servings per $d$. A strong inverse association between whole grain intake and ischaemic stroke risk was observed, with age-adjusted RR of 0.57 (95\% CI $0.42,0.78 ; P=0.003$ for trend) for stroke in the highest quintile of whole grain intake compared with the lowest quintiles of intake. The multivariate RR between the two extreme quintiles was 0.69 (95\% CI 0.50, 0.98; $P=0.08$ for trend). A strong inverse association between whole grain intake and CHD (both fatal and non-fatal) risk was also found. The age- and smoking-adjusted RR across increasing quintiles of whole grain intake were $1 \cdot 00,0 \cdot 87,0 \cdot 82$, 0.72 and 0.67 (95\% CI 0.54, 0.84; $P<0.001$ for trend). Adjustment for several dietary and non-dietary CHD risk factors gave a RR of $0.75(95 \%$ CI $0.59,0.95 ; P=0.01$ for trend) for the comparison of the extreme quintiles of intake.

A meta-analysis carried out by Anderson et al. (2000) of twelve population-based cohort studies indicated that those individuals with the highest intake of whole grain have an adjusted risk for CHD of 0.74 (95 \% CI 0.64, 0.84) compared with individuals with the lowest intake of whole grains. Whole grain intake was also found to have a stronger association with protection from CHD than intakes of cereal fibre, vegetables or fruits. These studies also suggest that the intake of three servings of wholegrain foods per $d$ may have an important cardio-protective effect.

All dietary surveys are liable to within-person error with self-reported diet, and misclassification of intake is always possible. Reporting of exact levels of intake using FFQ may have relatively poor accuracy because diet is highly variable from day to day, and as a result, actual amounts eaten are

Table 3. Intake of whole and refined grain among 38470 lowa women in 1986 (from Jacobs et al. 1999) (Values are medians and ranges)

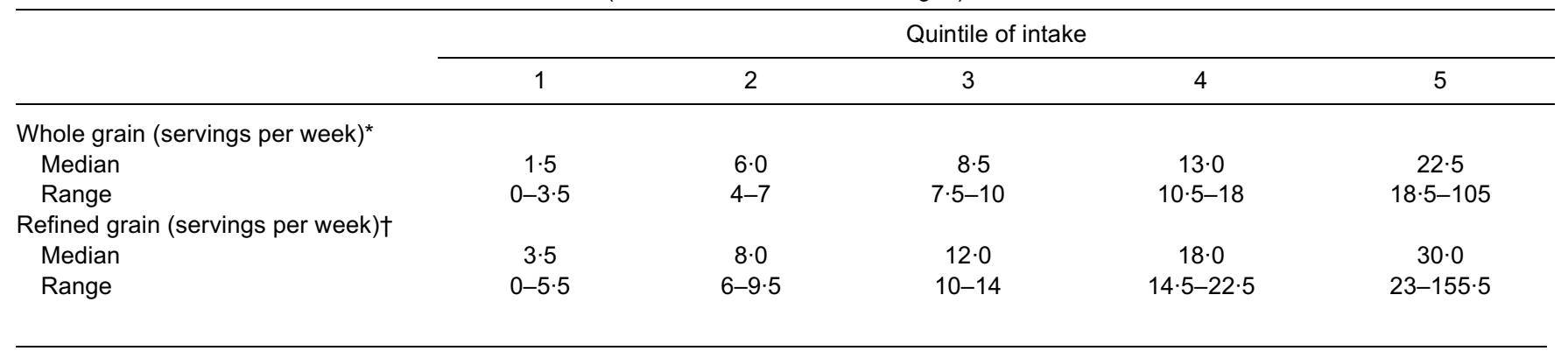


difficult for participants to reconstruct (Jacobs et al. 1998a). In many parts of the world whole grain intake appears to be positively associated with other health behaviours, so that confounding with other dietary and lifestyle factors is a possibility (Jacobs et al. 1998a). In all studies cited, participants who had high intakes of wholegrain foods also had numerous other favourable dietary and lifestyle characteristics. However, adjustment for many of these variables did not remove the inverse association between whole grain intake and risk for heart disease, with $23-40 \%$ reductions in observed risk in consumers with high whole-grain or dietary fibre intakes compared with those consuming little or no wholegrain foods or dietary fibre.

Few feeding studies have been conducted on the biological effects of increasing consumption of whole grains, and thus mechanisms to explain this putative cardioprotective effect remain unclear. Evidence for improved blood lipid profiles as a consequence of consuming increased quantities of wholegrain foods is available from Bruce et al. (2000), who fed twelve hyperlipidaemic subjects with a diet high in whole and unrefined foods compared with a control diet of refined foods. The test diet was described as 'phytochemical-rich' and included dried fruits, nuts, tea, wholegrain products and more than six servings of fruit and vegetables per $d$. Subjects consumed the refined food diet for the first 4 weeks of the study and then switched to the wholefoods diet for 4 weeks. Consumption of the whole foods diet resulted in a marked reduction in serum cholesterol and LDL-cholesterol concentrations, improved colon function and decreased the need for oxidative defence mechanisms. These factors are proposed as biomarkers of decreased risk of chronic disease (Slavin et al. 2001).

\section{Whole grains and cancer}

Diet plays a major role in the aetiology and prevention of cancer. Overall, there is considerable support for inverse associations between cancer risk and intakes of vegetables, fruits, whole grains, dietary fibre, certain micronutrients and certain types of fats, as well as physical activity. Direct relationships between diet and cancer have also been found for intakes of total and saturated fat, obesity and food preparation methods such as salting, smoking and pickling foods and high-temperature cooking of meats (Greenwald et al. 2001).

Whole grains are important sources of insoluble fibres, which are important for optimising bowel transit time and faecal weight, thereby reducing risk of bowel cancer (Cummings et al. 1992). Insoluble fibres undergo fermentation in the large intestine, producing short-chain fatty acids such as butyrate, an important suppresser of tumour formation (McIntyre et al. 1993). As already mentioned, whole grains also contain many different antioxidants and phyto-oestrogens, which are believed to be important in cancer prevention (Slavin, 2000). Whole grains also favourably mediate glucose response, which has been suggested as being protective against colon and breast cancer (Slavin, 2000).

Levi et al. (1999) used a case-control study in Switzerland of 223 male and female patients with colon cancer and 491 controls aged 27-74 years to assess the relationship between certain foods and risk for colon cancer. Information on habitual diet was gathered using a FFQ. Their results showed significant direct associations between refined grains (odds ratio (OR) 1.8 for highest tertile of intake), red meats (OR 2.2) and pork and processed meat (OR 2.9) and risk for colon cancer. Foods that showed significant inverse relationships with cancer risk were whole grains (OR 0.5), raw vegetables (OR 0.5), cooked vegetables (OR 0.4), citrus and other fruits (OR 0.5), garlic (OR 0.3) and coffee (OR 0.4).

Jacobs et al. (1999) also reported a reduction in cancer risk for all cancers studied in participants in the Iowa Women's Health Study who had a high whole grain consumption. The multivariate hazard rate ratio was 0.86 (95\% CI $0.76,0.97 ; P=0.005$ for trend) for the comparison of extreme quintiles of intake. Findings were similar among wholegrain bread consumers in the Norwegian County Study, with multivariate hazard rate ratios of $0.79(95 \% \mathrm{CI}$ 0.62, 1.02; $P=0 \cdot 07$; Jacobs et al. 2001).

Whole grain consumption is inversely associated with upper digestive cancers (Bosetti et al. 2000; Levi et al. 2000). Levi et al. (2000) reported protective effects of whole grains on risk for cancers of the oral cavity and pharynx (OR 0.6 for the highest tertile of intake), the oesophagus (OR 0.3 ) and larynx (OR 0.7 ), while refined grain intake displayed a direct relationship with risk for cancers at all three sites (OR 1.9, 3.7 and 4.0 respectively).

The Iowa Women's Health Study revealed a tendency for a higher risk of breast cancer in women in the highest quintile of whole grain intake, but this association was not significant and the authors concluded no association between refined or whole grain intakes with risk for postmenopausal breast cancer (Nicodemus et al. 2001). This finding is consistent with that of Terry et al. (2001), who studied major dietary patterns and risk for breast cancer. No association was found between risk for breast cancer and a 'healthy' dietary pattern (characterised by foods such as fruit, vegetables, fish, poultry, low-fat dairy products and whole grains) or 'Western' pattern (characterised by foods such as red and processed meats, refined grains, fats and sweets).

Chatenoud et al. (1998) carried out a systematic review of a series of hospital-based case-control studies to analyse the relationship between whole grain intake and risk for cancer at several sites. Cases were patients with histologicallyconfirmed cancers at oral and pharynx ( $n$ 181), oesophagus ( $n$ 316), larynx ( $n$ 242), stomach ( $n$ 745), colon ( $n$ 828), rectum $(n$ 498), liver ( $n$ 428), gallbladder ( $n$ 60), breast ( $n$ 3421), endometrium ( $n$ 750), ovaries ( $n$ 971), prostate gland ( $n$ 127), bladder ( $n$ 431), kidneys ( $n$ 190) and thyroid gland ( $n$ 208). There were also eighty cases of Hodgkin's disease and 200 cases of non-Hodgkin's lymphomas, and 120 cases of multiple myelomas. The control group consisted of 3220 male patients and 4770 female patients treated for a wide spectrum of acute non-neoplastic conditions at the same network of hospitals where cases had been identified. All control and case patients were $<75$ years. Dietary information was gathered using a FFQ administered in hospital by an experienced interviewer, and patients were followed for 8 years for colo-rectal cancer and 13 years for other cancers. Results showed a consistent pattern of protection of wholegrain foods for all cancer sites considered 
except thyroid. The tests for trend in risks were significant for all neoplasms except those associated with the pancreas, endometrium and prostate, Hodgkin's disease and multiple myeloma. The OR (adjusted for age, gender, education, smoking habits, alcohol intake and BMI) for oral, pharangeal or oesophageal cancers was $0.3(95 \%$ CI $0.2,0 \cdot 5 ; P \leq 0.01$ for trend) and that for laryngeal cancer was $0 \cdot 2$ (95\% CI $0 \cdot 0$, $0.5 ; P \leq 0.01$ for trend) for the comparison of the highest category of whole grain intake with the lowest category of intake. Corresponding OR were 0.4 for bladder and kidney, 0.5 for stomach, colon and gallbladder, 0.6 for ovary and liver, 0.7 for rectum, 0.8 for pancreas and prostate, 0.9 for breast and endometrium and about 0.5 for lympho-reticular neoplasms. The strength of the association varied among cancer sites but was consistent across strata of main covariates. Results were not notably modified when fruit or vegetables were included in the analysis.

Further support for the hypothesis that whole grain intake is inversely associated with several cancers is provided by Jacobs et al. (1998a) in a meta-analysis of forty case-control studies encompassing twenty cancer sites, conducted between 1985 and 1997. Dietary assessment in these studies was conducted using four different types of questionnaire, varying in the amount of information on whole grain intake levels and sources. Many descriptors were used to depict whole grain intake, including brown bread, crispbread, wholemeal bread, non-white bread, wholegrain bread, highfibre cereal, whole grains, wholegrain cereal, wholegrain pasta and wholegrain foods. To enable comparison across studies, quantities given were approximately translated into standard servings of $30-50 \mathrm{~g}$ and intakes were categorised for entry into dose-response analyses. The quantity of grain per serving was unknown. The most adjusted OR for the category with the highest $v$. the lowest intake of whole grain in each publication was selected for analysis. All reported OR according to level of intake were also recorded and used in dose-response analyses. In the forty published reports high $v$. low intake of wholegrain foods had an $\mathrm{OR}<1$ in forty-six of fifty-one cancer mentions (90\%), $55 \%$ of which achieved statistical significance. The pooled OR for all fifty-one mentions was highly significant at 0.69 (95\% CI $0.61,0.77)$. After removing six mentions that contained shortcomings, there were forty-three of forty-five (96\%) mentions that had OR $<1$, of which $58 \%$ were significant. The pooled OR for the forty-five mentions was 0.66 (95\% CI $0.60,0.72)$. The pooled OR for high $v$. low intake of whole grain across different dietary questionnaire types was $0.59-0.78$ with significance maintained in each case. The OR according to type of cancer was identified as $<1$ for nine of ten for colo-rectal cancers and polyps, seven of seven mentions for gastric cancer, six of six mentions for other digestive tract cancers, seven of seven mentions for hormone-related cancers, four of four mentions for pancreatic cancer, two of three mentions for brain cancer and eight of eight mentions for seven other cancers. Dose-response relationships were studied according to type of diet questionnaire, and comparisons made with a low-consumption category. A downward trend in pooled OR corresponded with an upward trend in whole grain consumption, independent of the type of dietary questionnaire. In studies where only the frequency of whole grain eating was reported, the pooled OR was 0.82 among occasional eaters and 0.59 among habitual eaters $(P<0.0001$ for trend). For studies that quantified intake but reported only tertiles of intake, the pooled OR was 0.81 for the second tertile and 0.62 for the third tertile $(P=0.0001$ for trend). In studies where the actual amount of whole grain was stated, the pooled OR decreased from 0.93 at the lowest level of whole grain intake to 0.85 at the highest level of intake $(P=0 \cdot 18$ for trend). Adjustment for several dietary, lifestyle and demographic covariates did not change the pooled OR, and it remained at $<1$ and significant as the number of adjusting factors increased.

The present review provides considerable evidence of an inverse association between whole-grain intake and several cancers. Dose-response analyses were strong and similar for two types of dietary questionnaires but weak for studies that used the most comprehensive questionnaires, thereby providing modest support for a dose-response relationship between whole grain intake and cancer. However, confounding with other dietary and lifestyle factors does not appear to explain the relationship between whole grains and cancer risk. Although it would be scientifically desirable to conduct clinical trials of whole-grain intake and cancer prevention to fully assess confounding as an explanation of these findings; such trials may not be feasible because of their required size, cost and duration (Jacobs et al. 1998a).

\section{Whole grains and diabetes}

Consumption of diets rich in high-glycaemic index (GI) foods is thought to promote insulin resistance, obesity and, in certain susceptible sections of the population, type 2 diabetes (Brand Miller, 1994). A number of whole grain foods and grain fibre sources may be beneficial in reducing insulin resistance with a concomitant improvement in glucose tolerance. The form, amount and method of cooking of these foods, as well as the age, gender and health characteristics of the subjects studied, are important factors in the effectiveness of the foods in altering these responses (Colagiuri \& Miller, 2002; Juntunen et al. 2002). In general, the greater the particle size (i.e. the less refined), the lower the glucose and insulin responses, and the greater the level of processing and refining, the higher the response. The milling of cereals makes starch more digestible and postprandial glycaemic and insulin responses can increase two- to threefold for refined cereals compared with coarsely-ground flour or whole grains (Colagiuri \& Miller, 2002). Grains that contain high levels of soluble $\beta$-glucans, e.g. oats, rye and barley, generally improve insulin sensitivity more effectively than wheat, which contains predominantly insoluble dietary fibre. Maize and rice can have either high or low GI. Replacing low-fibre grain foods such as maize or white bread with wholegrain higher-fibre products is likely to reduce the risk of developing insulin resistance and obesity (Hallfrisch $\&$ Behall, 2000). Consumption of whole grains from a variety of sources has been shown to be effective in improving insulin sensitivity in a study of overweight hyperinsulinaemic adults who were free from diabetes or other chronic conditions (Pereira et al. 2002).

As an adjunct to The Nurses' Health Study, the relationship between dietary GI, low fibre intake and risk 
of type 2 diabetes was examined using 65173 women aged 40-65 years from the original cohort followed for 6 years (Salmeron et al. 1997b). A dietary GI value (glycaemic load) was derived for each participant as: (sum of the products of the carbohydrate content per serving for each food $\times$ the average number of servings of that food per $\mathrm{d} \times$ its GI) $\div$ the total amount of carbohydrate. During the follow-up period 915 incident cases of type 2 diabetes were documented. The study found that diets with a high glycaemic load and low cereal fibre content were positively associated with risk of type 2 diabetes, independently of other dietary factors and known risk factors. Cereal fibre showed a strong inverse relationship with risk of diabetes, having an RR (adjusted for age, BMI, alcohol intake, smoking status and physical activity) of 0.72 (95\% CI 0.58 , $0.90 ; P=0.001$ for trend) in the highest quintile of cereal fibre intake (median $7.5 \mathrm{~g} / \mathrm{d}$ ) compared with the lowest quintile of intake (median $2.0 \mathrm{~g} / \mathrm{d}$ ). The combination of a high glycaemic load and low cereal-fibre intake further increased the risk of diabetes (RR 2.5 (95\% CI 1·14, 5.51)) compared with a low glycaemic load and high cereal-fibre intake. The results imply an important role for whole grains in reducing risk of diabetes. Other studies have reported similar results (again for women; Liu et al. 2000a; Meyer et al. 2000).

The association between whole and refined grain intake and risk of type 2 diabetes for men was examined as part of the Health Professionals Follow-up Study (Fung et al. 2001). A total of 42898 men free from diabetes and CVD at baseline were followed for 12 years, during which time 1197 incident cases of diabetes were documented. The RR of developing diabetes, adjusted for age, physical activity, energy intake, smoking, fruit and vegetable intake, alcohol consumption, family history of diabetes and BMI, was $0 \cdot 70$ (95\% CI $0.57,0.85 ; P=0.0006$ for trend) for men in the highest quintile of whole grain intake compared with those in the lowest quintile of intake. Salmeron et al. (1997a) reported a similar association between diabetes risk and cereal fibre intake in men.

\section{Whole grains and cholesterol}

Substitution of oat-based cereals for regular carbohydrate sources has been shown to reduce total cholesterol and LDL-cholesterol (VanHorn et al. 1991; Johnston et al. 1998). Brown et al. (1999) carried out a meta-analysis of sixty-seven controlled trials to quantify the cholesterollowering effect of major dietary soluble fibres. Fibres from oat products, psyllium, pectin and guar gum were studied and each source was shown to markedly lower total cholesterol. A practical dose range $(2-10 \mathrm{~g} / \mathrm{d})$ of soluble fibre was associated with a small but significant reduction in total cholesterol $(-0.045 \mathrm{mmol} / 1$ per g soluble fibre $(95 \%$ CI -0.054, -0.035)). A marked decrease in LDL-cholesterol was also observed $(-0.057 \mathrm{mmol} / \mathrm{l}$ per g soluble fibre $(95 \%$ CI $0 \cdot 070,-0 \cdot 044)$ ). Triacylglycerols and HDL-cholesterol were not significantly affected by soluble fibre.

Johnston et al. (1998) investigated the cholesterollowering effect of a ready-to-eat wholegrain-oat breakfast cereal in 124 hypercholesterolaemic males and females aged $40-70$ years. These volunteers consumed daily approx- imately $85 \mathrm{~g}$ oat breakfast cereal or maize-based breakfast cereal (control) for 6 weeks. Compared with the control group, the group consuming the oat breakfast cereal achieved approximately $4 \%$ reductions in the concentrations of total cholesterol and LDL-cholesterol and apoprotein B ( $P=0 \cdot 0008,0 \cdot 0065,0 \cdot 02$ respectively).

\section{Whole grains and obesity}

Holt \& Miller (1994) demonstrated that the processing of cereals is not only an important determinant of the glycaemic and insulin response, but also affects the level of postprandial satiety. In their study ten healthy participants received equivalent carbohydrate portions of four test meals of matching nutritional composition, based on whole grains, cracked grains or coarse or fine wholemeal flour. Plasma and insulin responses were the same as those predicted for the range of flours, i.e. highest for fine-flour test meal and lowest for the wholegrain test meal. However, satiety responses showed reverse rankings, with the fine flour test meal having the lowest satiety response (area under the curve 231.4 (SE 31.6) rating scale units.120 min), whereas the wholegrain test meal gave the highest satiety response (area under the curve 318.4 (SE 29.3) rating scale units $120 \mathrm{~min}$ ).

Ludwig et al. (1999) investigated the effects of dietary GI on voluntary food intake in obese male teenage subjects. Volunteers received identical isoenergetic meals at breakfast and lunch that had low, medium or high GI. During the $5 \mathrm{~h}$ post-lunch, voluntary energy intake after the high-GI meals $(5.8 \mathrm{MJ})$ was $53 \%$ greater than that after the medium-GI meal $(3.8 \mathrm{MJ})$ and $81 \%$ greater than that after the low-GI meal $(3 \cdot 2 \mathrm{MJ})$.

Although the relationship between food intake patterns and BMI or obesity is not clear-cut (Togo et al. 2001), increasing whole grain consumption is, theoretically, a useful dietary strategy to reduce the energy density of the diet, thereby aiding weight-loss efforts or minimising weight gain (Walker \& O’Dea, 2001). Indeed, increasing whole grain, fruit and vegetable intakes within a dietary intervention aimed at reducing dietary fat intake, aided by nutrition counselling, has been shown to be effective in certain individuals (Stevens et al. 2002).

\section{Whole grain health claims}

The scientific evidence linking whole grain intake with chronic disease prevention motivated the Food and Drug Administration to allow a health claim and, through the US Department of Agriculture, to warrant new dietary guidelines for the US population: 'Eat a variety of grains daily, especially whole grains'. Food grains form the base of the Food Guide Pyramid in the USA with the US Department of Agriculture and the Department of Health recommending six to eleven servings of grains per d, at least three of which should be whole grain (Slavin et al. 2001). The health claim: 'Diets rich in wholegrain foods and other plant foods and which are low in total fat, saturated fat, and cholesterol may reduce the risk of heart disease and some cancers' was approved for use on food labels of products that contain at least $51 \%(\mathrm{w} / \mathrm{w})$ whole grain (Food and Drug 
Administration, 1999). In the UK the 'Balance of Good Health' recommends that grains, potatoes and other starchy carbohydrates constitute about one-third of the diet (Health Education Authority, 1995). There are no specific guidelines for intakes of whole foods, although choosing high-fibre options where possible is advised. Recent campaigns in the UK led by the British Nutrition Foundation and those sponsored by industry have attempted to raise awareness among consumers of the health benefits of whole grains based on maintenance of cardiovascular health. These schemes have developed whole grain messages that can be communicated effectively through various health professionals and the media to help consumers identify wholegrain foods and products. The Joint Health Claims Initiative (2002) have recently authorised a health claim for wholegrain products (meeting the same criteria for classification of whole grain as US requirements) in the UK, which states: 'People who have a healthy heart tend to eat more whole grain foods as part of a healthy lifestyle'.

\section{Recommended intakes and consumption patterns}

In recent times substantial attention has been paid to the health effects of saturated fats and fruit and vegetable intakes, with little public attention directed to the importance of whole $v$. refined grains, which may contribute to population whole grain intakes falling short of recommendations. Food disappearance data for the USA show that total grain intake has decreased from $36.2 \%$ food energy in $1909-19$ to $23.3 \%$ food energy in 1990 . Wholegrain intake displays a modest increase over time but its contribution to food energy is minimal, at $1.4 \%$ in 1990 (Jacobs et al. 1999).

Table 3 shows intake levels of whole and refined grains divided into quintiles for participants of the Iowa Women's Health Study in 1986 (Jacobs et al. 1999). Those in the highest quintile had a median intake of 22.5 servings per week ( $3 \cdot 2$ servings/d), just above current US dietary recommendations. The range of intake within this quintile was very wide, with the lower value in the range, 18.5 servings per week, being less than the recommended intake,. Of this study cohort $>80 \%$ failed to reach the target intake, $40 \%$ consumed one or less serving per $\mathrm{d}$ and $>20 \%$ consumed virtually no whole grains. The Nurse's Health Study reported generally lower consumption rates among the 38-63-yearold participants, with median intakes of $0 \cdot 13,0 \cdot 43,0 \cdot 85,1 \cdot 31$ and 2.70 servings per $\mathrm{d}$ in quintiles $1-5$ respectively (Liu et al. 1999).

Albertson \& Tobelmann (1995) analysed food consumption data from the Market Research Corporation of America to establish consumption levels of grain and wholegrain foods among 9165 individuals. Grain intake was quantified as the number of eating occasions and data were categorised according to age-groups, 2-18 years and $\geq 19$ years. Of young Americans in this study $>50 \%$ and approximately $70 \%$ of the older age category reported less than three eating occasions of grain products (whole or refined) per $d$. Whole grain eating occasions of less than one per $\mathrm{d}$ were reported by 90 and $73 \%$ of the younger and older age categories respectively. About one-fifth of both age categories consumed no whole grains.
US National Food Survey data reveal whole-grain intake to be extremely low (Adams \& Engstrom, 2000a; Cleveland et al. 2000). Dietary information from 9323 individuals aged $\geq 20$ years, gathered through the US Department of Agriculture's Continuing Survey of Food Intakes by Individuals, was analysed for whole grain intakes (Cleveland et al. 2000). Only $8 \%$ met the recommendation to consume at least three servings of whole grains per $\mathrm{d}$ and only $36 \%$ consumed more than one serving per $\mathrm{d}$. Of the $65 \%$ consuming less than one serving per $\mathrm{d}$, half consumed no whole grains. Consumers of whole grains meeting the target intake were more likely to be male, white, of higher socio-economic status, a non-smoker, a frequent exerciser, a user of vitamin-mineral supplements and not overweight. Consumers of whole grains also had better nutrient profiles than non-consumers and were more likely to meet recommendations for other pyramid constituents, such as fruit and vegetables and dairy products.

Information on whole-grain intakes in the UK is limited but has recently been undertaken by Lang et al. (2003) using data from the National Dietary Survey of British Adults (1986-7) and the National Diet and Nutrition Survey of People aged 65 years and over (1994-5). In this report a serving of whole grain was identified on each occasion that a wholegrain food code appeared in a dietary record for each individual (defined according to US requirements, i.e. $51 \%$ (w/w) whole grain content), regardless of portion size. Using this criterion, approximately one-third of adults from both surveys failed to consume whole grains on a daily basis and $>90 \%$ consumed less than three servings per d. Median servings per week were $2 \cdot 0$ for males and $3 \cdot 0$ for females. Whole grain intake was lowest in the 16-24 year age category and highest among 55-64-year-olds in the 1986-7 survey. Consumption varied according to location, with differences observed between gender. Scotland and Wales had the lowest median number of servings per week for both men and women in the 1986-7 survey, while the Midlands and East Anglia showed the highest intakes for men and women. In both surveys whole grain intake was associated with higher social class and abstinence from smoking. The study did not quantify whole grain intake in terms of actual amount consumed and therefore intakes are likely to be underrepresented and not directly comparable with US consumption patterns.

\section{Strategies to increase whole grain consumption}

In general, therefore, whole grain intake is extremely low among most consumers. Studies from both the USA and the UK that have quantified whole-grain intakes from specific food sources found breads and breakfast cereals to be the major contributors (Jacobs et al. 1999; Cleveland et al. 2000; Smith et al. 2001b; Lang et al. 2003). Adams \& Engstrom (2000b) postulated that inferior taste, time constraints, unfamiliarity with wholegrain foods and what constitutes 'whole grain' and a lack of knowledge of the health benefits of whole grains contribute to poor consumer uptake of whole $v$. refined foods. In a questionnaire-based study of populations in Newcastle upon Tyne and Chester (Deeside, UK), Smith S et al. (2001) have reported low consumption levels of wholegrain products, especially 
among consumers $<25$ years of age compared with older individuals. In this study it was also found that a large number of respondents (18-34\%) were unaware of the link between whole grains and chronic disease.

More recently, an intervention study aimed at increasing consumption of wholegrain foods was undertaken for which preliminary results have been published (Smith et al. $2001 a, b)$. In this study healthy non-dieting participants aged 25-40 years were provided with a selection of wholegrain foods available from local supermarkets to incorporate into their diets. Sufficient quantities were provided to enable inclusion of at least one whole grain option with every meal of the day for a period of $14 \mathrm{~d}$, with the aim of achieving five servings of whole grains per d. Dietary intakes were recorded at baseline and during the second week of intervention using a $7 \mathrm{~d}$ food diary and the Ministry of Agriculture Fisheries and Food photographic atlas of food portion sizes (Nelson et al. 1997) to quantify intakes. The intervention involved delivery of positive health messages based on the need to increase consumption of whole grains and emphasising the health benefits arising from increased whole-grain consumption. Volunteers also received advice on how to recognise wholegrain products and how to incorporate them into their diet. At 1 month post-intervention volunteers participated in a semi-structured focus group discussion to explore attitudes towards the dietary changes, sustainability of the intervention intakes and perceived barriers to change. During the intervention period whole grain consumption rose from an average of $3 \cdot 2$ servings per $\mathrm{d}$ in men and 0.7 servings in women to 7.0 and 5.4 servings per $\mathrm{d}$ respectively. This increase was associated with an increase in NSP consumption for both groups $(P<0.001$ for women), and a change in the contribution of macronutrients to total energy intake. During the intervention period, the percentage energy from total fat fell from $32 \cdot 1$ to 28.5 in men $(P<0.05)$ and from 34.5 to 30.3 in women $(P<0.01)$. In the latter group this reduction in fat intake was balanced by a significant increase in carbohydrate intake (from $46 \cdot 0$ to $48.4 \% ; P<0.05)$. There was a general positive attitude towards the dietary changes associated with increased whole grain consumption. Rating of the new dietary pattern averaged $6 \cdot 1$ rating scale units (range $1 \cdot 0-9 \cdot 9$; ratings scale went from 0 'I really hate it' to 10 'I really love it'). When interviewed 1 month after the intervention period participants expressed the view that they were prepared to continue consuming wholegrain foods but to a lesser extent than intervention levels, reflecting problems encountered during the study period. These problems and barriers to consumption included out-of-home food consumption, personal and household members' preferences for other products, limited variety and availability of wholegrain foods, and intestinal discomfort (bloating) reported by many females during the intervention period. For those individuals who do consume wholegrain foods regularly, bread and breakfast cereals are the most popular sources based on convenience, taste and availability (Jacobs et al. 1998b; Liu et al. 1999; Richardson, 2000; Smith S et al. 2001). Breakfast is, therefore, an important meal to target for intervention. A further study was undertaken to investigate the dietary ramifications of consumption of whole grains at breakfast in twenty healthy 18-26-year-old male and female volunteers who were habitual breakfast eaters (for preliminary results, see Smith et al. 2002). Volunteers received four breakfasts based on cereal or toast with refined and wholegrain alternatives for both types of breakfast. Quantities were self-selected at the first breakfast meal for both types of breakfast and the volunteers received the same quantity at each subsequent breakfast meal. Each breakfast was consumed twice in a randomised order over the study period giving eight breakfast sessions in total per individual. Dietary information was gathered using food diaries completed on study days and portions quantified with the atlas of food portion sizes, as described previously. The results showed no differences in macronutrient intakes between days on which refined and whole grain alternatives were consumed for either breakfast type. There were, however, several differences observed in micronutrient intakes. The significantly higher intakes of folate and some B-vitamins on days when the refined-grain cereal was consumed reflect the effect of fortification of the refined cereal compared with the wholegrain cereal that is not fortified. NSP intake was higher for days when the whole grain breakfasts were consumed $(16 \mathrm{~g}$ for white toast $v .19 \mathrm{~g}$ for wholemeal toast $(P=0 \cdot 07)$ and $13 \mathrm{~g}$ for refined cereal $v$. $19 \mathrm{~g}$ for wholegrain cereal $(P<0 \cdot 001))$. Although participants achieved recommended intakes for adults of all vitamins and minerals for both breakfast types, only those consuming the fortified breakfast cereal achieved the higher level of folate intake required for women during conception and early pregnancy $(414 \mu \mathrm{g}$ for refined cereal $v 290 \mu \mathrm{g}$ for the other breakfast options). Na intake was significantly lower for days on which the wholegrain cereal was consumed (3.8 $\mathrm{g}$ for refined cereal (Cornflakes; Kellogg's, Manchester, UK) v. $3.0 \mathrm{~g}$ for wholegrain cereal (Shredded Wheat; Nestlé, Croydon, Surrey, UK; $P=0 \cdot 007)$. This observation again reflected the specific composition of the wholegrain cereal, to which $\mathrm{NaCl}$ is not added during processing. Analysis of food intake subsequent to the breakfast meal revealed no differences in intakes of any nutrient, implying that the differences observed were attributable to the type of breakfast consumed.

\section{Summary}

Whole grains deliver a wide range of important nutrients and phytochemicals to our diets, which may work in synergy to promote health and help prevent disease. Although there are limitations to the interpretation of epidemiological data, and in particular the definition and quantification of whole-grain consumption, there is strong evidence to support the link between whole grains and health benefits. Based on epidemiological studies and biologically plausible mechanisms, there is developing scientific evidence that shows that regular consumption of wholegrain foods reduces rates of CHD and several forms of cancer (Slavin et al. 2001). Regular consumption of whole grains may also help regulate blood glucose levels and so reduce the risk of development of type 2 diabetes for susceptible individuals (Slavin et al. 2001). Although many of the biologically-active substances in wholegrain foods have health-promoting properties, the mechanisms of action for whole grains in disease prevention are not fully understood. 
An important direction for future research is to elucidate their exact role and detect the most active constituents. Identification of such components may be useful in terms of processing techniques, which could be adapted or developed to minimise the loss of the important active substances (Slavin et al. 1997).

Important considerations arising from the epidemiological evidence to date are the questions of protection thresholds, the dose-response relationship between whole grain intake and reduced risk of disease, and the influence of other dietary and lifestyle factors in producing a protective effect. Jacobs et al. (1998b) observed an increased risk of disease in the highest quintile of whole grain intake compared with the preceding quintile in the Iowa Women's Health Study, which could be an indication of a protection threshold. This trendwas not found, however, in the Nurses' Health Study (Liu et al. 1999), although generally lower consumption levels were reported across quintiles of intake in this study group compared with the Iowa Women's Health Study. Further information of the long-term effects of very high levels of intake of whole grains is required.

Jacobs et al. (1998a) reported consistent protective effects of whole grain consumption and risk of several cancers, but found modest support for a dose-response relationship.

The epidemiological studies to date have found that individuals who consume high levels of whole grains are also likely to have many other health-promoting dietary practices, and the effects of these practices and those of whole grains may not be mutually exclusive. Modification of several dietary constituents will probably have a greater effect than simply increasing whole grain consumption by substitution of refined products (Burr et al. 1989). Thus, it is important to retain context in communicating advice on increasing whole grain consumption, as the UK Joint Health Claims Initiative health claim clearly has attempted to do, stressing the importance of whole grains as part of a healthy diet and lifestyle.

Studies indicate that whole grain consumption is extremely low and many barriers exist to the adoption of whole grains as foods regularly consumed. However, it has been clearly demonstrated that increasing whole grain consumption, by the use of appropriate food products, can improve nutrient profiles towards current recommendations, particularly for cereal-fibre and $\mathrm{Na}$ intakes. Dissemination of the whole grain health message is critical in increasing consumer knowledge and awareness of the importance and sources of whole grains. The food industry also has an important role to play in increasing the variety of whole grain foods available to consumers. Such products also need to meet with consumer acceptance in terms of the hedonic characteristics of the food to facilitate sustained usage. Breakfast foods may be an important intervention target for increasing whole grain consumption. Indeed, the present breakfast study has shown that for this meal very favourable changes in nutrient intakes can be achieved through a dietary change that is simple and, potentially, readily transferable.

\section{References}

Adams JF \& Engstrom A (2000a) Dietary intake of whole grain vs. recommendations. Cereal Foods World 45, 75-78.

Adams JF \& Engstrom A (2000b) Helping consumers achieve recommended intakes of whole grain foods. Journal of the American College of Nutrition 19, 339S-344S.

Adlercreutz H (1995) Phytoestrogens - epidemiology and a possible role in cancer protection. Environmental Health Perspectives 103, 103-112.

Adlercreutz H (2002) Phyto-oestrogens and cancer. Lancet Oncology 3, 364-373.

Adlercreutz H \& Mazur W (1997) Phyto-oestrogens and Western diseases. Annals of Medicine 29, 95-120.

Albertson AM \& Tobelmann RC (1995) Consumption of grain and whole-grain foods by an American population during the years 1990 to 1992. Journal of the American Dietetic Association 95, 703-704.

Anderson JW, Hanna TJ, Peng X \& Kryscio RJ (2000) Whole grain foods and heart disease risk. Journal of the American College of Nutrition 19, 291S-299S.

Andlauer W \& Furst P (1998) Antioxidative power of phytochemicals with special reference to cereals. Cereal Foods World 43, 356-359.

Baublis AJ, Clydesdale FM \& Decker EA (2000a) Antioxidants in wheat-based breakfast cereals. Cereal Foods World 45, 71-74.

Baublis AJ, Lu C, Clydesdale FM \& Decker EA (2000b) Potential of wheat-based breakfast cereals as a source of dietary antioxidants. Journal of the American College of Nutrition 19, 308S-311S.

Bosetti C, Negri E, Franceschi S, Conti E, Levi F, Tomei F \& La Vecchia C (2000) Risk factors for oral and pharyngeal cancer in women: a study from Italy and Switzerland. British Journal of Cancer 82, 204-207.

Brand Miller JC (1994) Importance of glycemic indexes in diabetes. American Journal of Clinical Nutrition 59, 747S.

British Nutrition Foundation (2001) The health benefits of whole grains. http://www.nutrition.org.uk

Brown L, Rosner B, Willett WW \& Sacks FM (1999) Cholesterollowering effects of dietary fiber: a meta-analysis. American Journal of Clinical Nutrition 69, 30-42.

Bruce B, Spiller GA, Klevay LM \& Gallagher SK (2000) A diet rich in whole and unrefined foods favorably alters lipids, antioxidant defenses, and colon function. Journal of the American College of Nutrition 19, 61-67.

Burr ML, Fehily AM, Gilbert JF, Rogers S, Holliday RM, Sweetnam PM, Elwood PC \& Deadman NM (1989) Effects of changes in fat, fish and fibre intakes on death and myocardial reinfarction: diet and reinfarction trial (DART). Lancet ii, 757-761.

Chatenoud L, Tavani A, La Vecchia C, Jacobs DR Jr, Negri E, Levi F \& Franceschi S (1998) Whole grain food intake and cancer risk. International Journal of Cancer 77, 24-28.

Cleveland LE, Moshfegh AJ, Albertson AM \& Goldman JD (2000) Dietary intake of whole grains. Journal of the American College of Nutrition 19, 331S-338S.

Colagiuri S \& Miller JB (2002) The 'carnivore connection' evolutionary aspects of insulin resistance. European Journal of Clinical Nutrition 56, 30-35.

Craig WJ (1997) Phytochemicals: Guardians of our health. Journal of the American Dietetic Association 97, S199-S204.

Cummings JH, Bingham SA, Heaton KW \& Eastwood MA (1992) Fecal weight, colon cancer risk, and dietary intake of nonstarch polysaccharides (dietary fiber). Gastroenterology 103, 1783-1789. 
Cuskelly GJ, McNulty H \& Scott JM (1996) Effect of increasing dietary folate on red-cell folate: Implications for prevention of neural tube defects. Lancet 347, 657-659.

Englyst HN \& Cummings JH (1988) An improved method for the measurement of dietary fibre and the non-starch polysaccharides in plant foods. Journal of the Association of Analytical Chemists 71, 808-814.

Food and Drug Administration (1999) Health claim notification for whole grain foods. http:// dms/flgrains.html

Fraser GE (1999) Associations between diet and cancer, ischemic heart disease, and all-cause mortality in non-Hispanic white California Seventh-day Adventists. American Journal of Clinical Nutrition 70, 532S-538S.

Fung TT, Hu FB, Pereira MA, Liu S, Stampfer MJ \& Colditz GA (2001) Whole grain intake and the risk of type 2 diabetes in men. American Journal of Epidemiology 153, 145.

Greenwald P, Cliford CK \& Milner JA (2001) Diet and cancer prevention. European Journal of Cancer 37, 948-965.

Hallfrisch J \& Behall KM (2000) Improvement in insulin and glucose responses related to grains. Cereal Foods World 45, 66-69.

Health Education Authority (1995) Enjoy Healthy Eating, The Balance of Good Health. London: HEA.

Holt SHA \& Miller JB (1994) Particle size, satiety and the glycaemic response. European Journal of Clinical Nutrition 48, 496-502.

Hu FB, Rimm EB, Stampfer MJ, Ascherio A, Spiegelman D \& Willett WC (2000) Prospective study of major dietary patterns and risk of coronary heart disease in men. American Journal of Clinical Nutrition 72, 912-921.

Jacobs DR Jr, Marquart L, Slavin J \& Kushi LH (1998a) Wholegrain intake and cancer: an expanded review and meta-analysis. Nutrition and Cancer 30, 85-96.

Jacobs DR Jr, Meyer KA, Kushi LH \& Folsom AR (1998b) Whole-grain intake may reduce the risk of ischemic heart disease death in postmenopausal women: the Iowa Women's Health Study. American Journal of Clinical Nutrition 68, 248-257.

Jacobs DR Jr, Meyer KA, Kushi LH \& Folsom AR (1999) Is whole grain intake associated with reduced total and cause-specific death rates in older women? The Iowa Women's Health Study. American Journal of Public Health 89, 322-329.

Jacobs DR Jr, Meyer HE \& Solvoll K (2001) Reduced mortality among whole grain bread eaters in men and women in the Norwegian County Study. European Journal of Clinical Nutrition 55, 137-143.

Jacobs DR Jr, Pereira MA, Meyer KA \& Kushi LH (2000) Fiber from whole grains, but not refined grains is inversely associated with all-cause mortality in older women: the Iowa Women's Health Study. Journal of the American College of Nutrition 19, 326S-330S.

Johnston L, Reynolds HR, Patz MH, Huntinghake DB, Schultz K \& Westereng B (1998) Cholesterol-lowering benefits of a whole grain oat ready-to-eat cereal. Nutrition in Clinical Care $\mathbf{1}$, 6-12.

Joint Health Claims Initiative (2002) Generic health claim for wholegrain foods and heart health. http://www.jhci.org.uk/ wholegrainheart.htm

Juntunen KS, Niskanen LK, Liukkonen KH, Poutanen KS, Holst JJ \& Mykkanen HM (2002) Postprandial glucose, insulin, and incretin responses to grain products in healthy subjects. American Journal of Clinical Nutrition 75, 254-262.

Knekt P, Reunanen A, Jarvinen R, Seppanen R, Heliovaara M \& Aromaa A (1994) Antioxidant vitamin intake and coronary mortality in a longitudinal population study. American Journal of Epidemiology 139, 1180-1189.

Kurzer MS \& Xu X (1997) Dietary phytoestrogens. Annual Review of Nutrition 17, 353-381.
Lang R, Jebb SA, Thane CW \& Bolton-Smith C (2003) Consumption of Wholegrain Foods by British Adults: Findings from Further Analysis of Two National Surveys. Public Health Nutrition (In the Press).

Levi F, Pasche C, La Vecchia C, Lucchini F \& Francheschi S (1999) Food groups and colorectal cancer risk. British Journal of Cancer 79, 1283-1287.

Levi F, Pasche C, Lucchini F, Chatenoud L, Jacobs DR \& La Vecchia C (2000) Refined and whole grain cereals and the risk of oral, oesophageal and laryngeal cancer. European Journal of Clinical Nutrition 54, 487-489.

Liu S, Manson JE, Stampfer MJ, Hu FB, Giovannucci E, Colditz GA, Hennekens CH \& Willett WC (2000a) A prospective study of whole grain intake and risk of Type 2 diabetes mellitus in US women. American Journal of Public Health 90, 1409-1415.

Liu S, Manson J, Stampfer MJ, Rexrode KM, Hu FB, Rimm EB \& Willett WC (2000b) Whole grain consumption and risk of ischemic stroke in women: A prospective study. Journal of the American Medical Association 284, 1534-1540.

Liu S, Stampfer MJ, Hu FB, Giovannucci E, Rimm E, Manson J \& Hennekens CH (1999) Whole-grain consumption and risk of coronary heart disease: results from the Nurses' Health Study. American Journal of Clinical Nutrition 70, 412-419.

Ludwig DS, Majzoub JA, Al-zahrani A, Dallal GE, Blanco I \& Roberts SB (1999) High glycemic index foods, overeating and obesity. Pediatrics 103, e26.

McIntyre A, Gibson PR \& Young GP (1993) Butyrate production from dietary fibre and protection against large bowel cancer in a rat model. Gut 34, 386-391.

Meyer KA, Kushi LH, Jacobs DR, Slavin J, Sellers TA \& Folsom AR (2000) Carbohydrates, dietary fiber, and incident type 2 diabetes in older women. American Journal of Clinical Nutrition 71, 921-930.

Miller HE, Rigelhof F, Marquart L, Prakash A \& Kanter M (2000a) Antioxidant content of whole grain breakfast cereals, fruits and vegetables. Journal of the American College of Nutrition 19, 312S-319S.

Miller HE, Rigelhof F, Marquart L, Prakash A \& Kanter M (2000b) Whole grain products and antioxidants. Cereal Foods World $\mathbf{4 5}$, 59-63.

Morris JN, Marr JW \& Clayton DG (1977) Diet and heart: a postscript. British Medical Journal 2, 1307-1314.

Nelson M, Atkinson M \& Meyer J (1997) A Photographic Atlas of Food Portion Sizes. London: MAFF.

Nicodemus KK, Jacobs DR \& Folsom AR (2001) Whole and refined grain intake and risk of incident postmenopausal breast cancer (United States). Cancer Causes and Control 12, 917-925.

Pereira MA, Jacobs DR, Pins JJ, Raatz SK, Gross MD, Slavin JL \& Seaquist ER (2002) Effect of whole grains on insulin sensitivity in overweight hyperinsulinemic adults. American Journal of Clinical Nutrition 75, 848-855.

Pietinen P, Rimm EB, Korhonen P, Hartman AM, Willett WC, Albanes D \& Virtamo J (1996) Intake of dietary fiber and risk of coronary heart disease in a cohort of Finnish men - The Alpha Tocopherol, Beta-Carotene Cancer Prevention Study. Circulation 94, 2720-2727.

Richardson DP (2000) The grain, the wholegrain and nothing but the grain: the science behind wholegrain and the reduced risk of heart disease and cancer. Nutrition Bulletin 25, 353-360.

Rimm EB, Ascherio A, Giovannucci E, Spiegelman D, Stampfer MJ \& Willett WC (1996) Vegetable, fruit, and cereal fiber intake and risk of coronary heart disease among men. Journal of the American Medical Association 275, 447-451.

Rimm EB, Stampfer MJ, Ascherio A, Giovannucci E, Colditz GA \& Willett WC (1993) Vitamin-E consumption and the risk of 
coronary heart disease in men. New England Journal of Medicine 328, 1450-1456.

Salmeron J, Ascherio A, Rimm EB, Colditz GA, Spiegelman D, Jenkins DJ, Stampfer MJ, Wing AL \& Willett WC (1997a) Dietary fiber, glycemic load, and risk of non-insulin-dependent diabetes mellitus in men. Diabetes Care 20, 545-550.

Salmeron J, Manson JE, Stampfer MJ, Colditz GA, Wing AL \& Willett WC (1997b) Dietary fiber, glycemic load, and risk of non-insulin-dependent diabetes mellitus in women. Journal of the American Medical Association 277, 472-477.

Shoff SM, Newcomb PA, Mares-Perlman JA, Klein BEK, Haffner SM, Storer BE \& Klein R (1998) Usual consumption of plant foods containing phytoestrogens and sex hormone levels in postmenopausal women in Wisconsin. Nutrition and Cancer 30, 207-212.

Slavin JL (1999) Health benefits of oligosaccharides. Journal of Nutraceuticals, Functional and Medical Foods 1, 43-55.

Slavin JL (2000) Mechanisms for the impact of whole grain foods on cancer risk. Journal of the American College of Nutrition 19, 300S-307S.

Slavin JL, Jacobs D \& Marquart L (1997) Whole-grain consumption and chronic disease: protective mechanisms. Nutrition and Cancer 27, 14-21.

Slavin JL, Jacobs D \& Marquart L (2000) Grain processing and nutrition. Critical Reviews in Food Science and Nutrition 40, 309-326.

Slavin JL, Jacobs D, Marquart L \& Weimer K (2001) The role of whole grains in disease prevention. Journal of the American Dietetic Association. 101, 780-785.

Smith A, Kuznesof S, Richardson, DP \& Seal, CJ (2001a) Effectiveness of dietary intervention strategies aimed at increasing consumption of whole grain or low- and reduced-fat products in free-living volunteers. Proceedings of the Nutrition Society 60, 178A.

Smith A, Richardson DP, Kuznesof S \& Seal CJ (2001b) Effectiveness and acceptability of a dietary intervention to increase consumption of whole grain products in free living individuals. In Whole Grain and Human Health, pp. 32-35 [K Liukkonen, A Kuokka and K Poutanen, editors]. Espoo, Finland: Technical Research Centre of Finland.

Smith AT, Kuznesof S, Richardson DP \& Seal CJ (2002) Impact of whole grain breakfast consumption on daily nutrient intakes. Proceedings of the Nutrition Society 61, 118A.
Smith S, Smith A, Richardson DP \& Seal CJ (2001) Regional variations in consumer knowledge and purchasing of whole grain foods. Proceedings of the Nutrition Society 60, 218A.

Southgate DAT (2000) Cereals and cereal products. In Human Nutrition and Dietetics, pp. 333-347 [JS Garrow, WPT James and A Ralph, editors]. London: Churchill Livingstone.

Stephen AM (1994) Whole grains - impact of consuming whole grains on physiological effects of dietary fiber and starch. Critical Reviews in Food Science and Nutrition 34, 499-511.

Stevens VJ, Glasgow RE, Toobert DJ, Karanja N \& Smith KS (2002) Randomized trial of a brief dietary intervention to decrease consumption of fat and increase consumption of fruit and vegetables. American Journal of Health Promotion 16, $129-134$

Terry P, Suzuki R, Hu FB \& Wolk A (2001) A prospective study of major dietary patterns and the risk of breast cancer. Cancer Epidemiology Biomarkers and Prevention 10, 1281-1285.

Thompson LU (1994) Antioxidants and hormone-mediated health benefits of whole grains. Critical Reviews in Food Science and Nutrition 34, 473-497.

Togo P, Osler M, Sorensen T \& Heitmann B (2001) Food intake patterns and body mass index in observational studies. International Journal of Obesity 25, 1741-1751.

Truswell AS (2002) Cereal grains and coronary heart disease. European Journal of Clinical Nutrition 56, 1-14.

VanHorn L, Moagstahlberg A, Liu K, Ballew C, Rut K, Hughes R \& Stamler J (1991) Effects on serum-lipids of adding oats to usual American diets. American Journal of Public Health 81, $183-188$

Walker KZ \& O'Dea K (2001) Is a low fat diet the optimal way to cut energy intake over the long term in overweight people? Nutrition Metabolism and Cardiovascular Diseases 11, 244-248.

Ward M (2001) Homocysteine, folate, and cardiovascular disease. International Journal for Vitamin and Nutrition Research 71, 173-178.

Wolk A, Manson JE, Stampfer MJ, Colditz GA, Hu FB, Speizer FE, Hennekens CH \& Willett WC (1999) Long-term intake of dietary fiber and decreased risk of coronary heart disease among women. Journal of the American Medical Association 281, 1998-2004. 